\title{
Potential Energy Benchmark for Lecture Timetable Problem
}

\author{
Bettoni Laura*, Zavanella Lucio E. \\ Department of Mechanical and Industrial Engineering, University of Brescia, via Branze 38, I-25123 Brescia, Italy
}

Corresponding Author Email: laura.bettoni@unibs.it

https://doi.org/10.18280/ti-ijes.632-409

Received: 17 January 2019

Accepted: 23 April 2019

Keywords:
course timetabling, energy scheduling,
potential energy benchmark

\begin{abstract}
Energy efficiency does not concern only building structures, and electrical and thermal systems, but also the management of the building as a whole. From the point of view of Universities, lectures timetabling is one of the most important issues in building management. However, until to now, the variables considered in the schedule of the lectures do not include energy consumption or, in general, sustainability indices. Nevertheless, the use of a lecture room requires the use of both electrical and thermal energy, differing in the energy requirement according to timing, season and geographical exposure. In this paper, the Potential Energy Benchmark (PEB) of lecture rooms is defined so as to assign priority, in the timetabling, to the most energy-efficient lecture rooms. The PEB measures the potential thermal energy required for warming up or cooling the room, as well as the potential electrical energy for lighting, in different time slots throughout the day. The PEB shifts depend on the structural constraints of the lecture room considered, such as its radiation and exposure to natural light. The final goal is to solve the lecture timetabling problem, minimizing energy consumption, and consequently the carbon footprint of the University in the view of teaching activities. Once the optimal energy planning has been identified, a comparison with the traditional planning will be proposed, so as to quantify the energy and $\mathrm{CO}_{2}$ savings reached.
\end{abstract}

\section{INTRODUCTION}

Legislative actions propose investments to increase the efficiency of energy utilization in buildings, industry, economy and agriculture. The Public Administration (PA) in Italy is invited to increase the energy efficiency of its buildings at least of $3 \%$ per year, according to the legislative decree 102/14 [1]. The structure insulation and the heating system renewal are usually the first actions undertaken to increase energy efficiency in building. These types of improvements require great investments and their pay back time is often in the 5-10 years range, or more. Too long time. The best energy reduction is the energy not used, as stated many times. Thus, optimization of the building management could be a good interpretation, avoiding the use of energy for lighting, heating and cooling.

The primary business of Universities is to supply lectures for students. The lecture timetable problem, because of its complexity, has been studied by many researchers. The problem is classified as a NP-complete one and it is solved using optimization algorithms, as well as genetic algorithms, tabu- search, graph methods and others. The objective function of the problem is to optimize the scheduling of the lecture rooms. The hard constraints must be fulfilled and the soft constraints should be satisfied, but with elasticity. The hard constraints regard the lecture room capacity, the overlapping between lectures of the same course and the overlapping of the lectures of the same professor. The soft constraints concern the timetabling preference of professors, the allowed lunchtime and others constraints customized by each University.

The timetabling problem does not concern energy implications in the assignment of the lecture rooms, i.e. energy use is not optimized in the timetable scheduling.

The focus of this paper is on the creation of an indicator useful for comparing the energy used by different lecture rooms. The Potential Energy Benchmark (PEB) allows to rank lecture rooms belonging to the same size, as a function of a lower use of energy, maintaining a high comfort level. Each lecture room has different "energy features", depending on the buildings structure, solar exposure, solar radiance and free intake from the external environment. The solar radiation changes during the day and among the seasons, and the free solar intake changes, too. Therefore, the Potential Energy Benchmark has been calculated for each lecture room, season and daily timeslot.

The timetable optimization has been modified to minimize energy consumption of lecture supply. The hard constraints have been preserved, while the soft constraints have been relaxed. The PEB has been included within the hard constraint set, and it has been used to choose the lecture room requiring less energy for the lecture service.

The remainder of the paper is organized as follows. The timetable problem, considering the energy efficiency of university buildings, is presented in Section 2. Successively, the variables influencing the indicator are shown and the Potential Energy Benchmark is introduced and calculated (Section 3). The energy used for the current timetable is assessed for the case of the University of Brescia (Section 4). Finally, Section 5 discusses a new timetable proposal, which considers an improved use of energy, and conclusion are drawn in Section 6. 


\section{BACKGROUND}

Lecture timetabling usually considers the optimization of lecture assignment to the lecture rooms. The satisfaction of professors and students is of primary importance. Different algorithms have been used to solve the problem. Some algorithms reduce the operational time, others optimize the constraints meeting. Each algorithm finds the best solution in scheduling.

However, an amount of energy is necessary to allow the teaching activity, i.e. when a lecture room is operating. Each lecture room requires a given quantity of energy, according to the features of the lecture room itself. The elements that influence the energy requirement are the electrical and thermal devices of the lecture room, its size, its ceiling and floor, the level of occupation during the lecture, the structure of the walls, the presence of windows and the orientation. To date, some researchers have introduced classification elements in the room assignment problem. Zheng Yang et al. [2] introduced the consumption of HVAC system (i.e. heating ventilation and air conditioning) in the assignment room problem. At first, they revisited the occupancy profile of the HVAC system in a realistic way. Then, they reassign occupants' room to improve energy efficiency. According to Mehreen S. Gul [3], the occupancy patterns have to be designed as similar as possible to reality, so as to optimize management and design control strategies for reducing energy consumption. Pan et al. [4], and Masoso and Globle [5] highlighted the importance of occupant behaviour on energy use in buildings.

Majumdar et al. [6] introduced the building parameters in the analysis of lecture rooms assignment, such as construction year, orientation, window areas, energy equipment and lighting system. They used a simulation software to validate their model and showed that the greater the accuracy of the parameters, the greater the model prediction. Those authors have introduced the energy issue in the assignment and scheduling problem. Song et al. [7] introduced energy optimization in course timetabling for university buildings. The minimization of energy use was included in the objective function of the genetic algorithm, to optimize the timetable problem. Sethanan et al. [8] investigated energy use so as to improve a lecture room-scheduling algorithm. They used a tabu search algorithm to solve the problem.

The present paper proposes a model to estimate the energy performance of the lecture rooms, during the day and for different seasons. Successively, the model is used to analyze the energy consumption of the current timetable at the University of Brescia. Finally, the indices have been used to create a new timetable, that minimizes energy use. This work differs from the previous ones for two reasons. The first is that a benchmark has been created to rank the lecture rooms available from the most to the less efficient one. Secondly, an assignment algorithm, based on the potential energy benchmark, has been used to create the timetable, i.e. no optimization algorithm has been used.

\section{POTENTIAL ENERGY BENCHMARK}

The Potential Energy Benchmark shows the potential energy required by a lecture room for one hour of use. The PEB comprises two types of energy consumption: thermal energy $(T E)$ and electrical energy $(E E)$. The thermal energy is both the energy used for heating the lecture room during the winter
$(T R w)$ and the cooling energy for refrigerating the lecture room in summer $(T R c)$. In autumn and springtime, the thermal system is off and only the air ventilation unit is on: thermal contribution is zero during those seasons. At this time, the electrical energy used by the HVAC system is not considered. The lighting of the lecture room is the only contribution involved for the electrical energy. The energy used in the laboratories or for specific devices is not considered in this paper, due to the difficulties to collect the energy consumption profile of the lab devices, which are also used irregularly. A further development will encompass the workrooms and HVAC consumption.

Some properties influence the Potential Energy Benchmark of a lecture room, such as the building structure (which allows to define the thermal transmittance of walls and windows) and the percentage of transparent surfaces (which allows the evaluation of the solar intake, affecting both thermal and electrical energy Requirements). Other influencing factors are the season $(s)$, which concerns the on-off operations of cooling or heating systems, the orientation of the building $(c)$, with respect to cardinal point, which allows to describe the solar irradiance. The irradiance changes during the day, thus the solar intake changes, too. The energy requirement of the lecture room changes, therefore, during the day. For this reason, the day has been split into three timeslots $(t)$. The first (a) from 8:30 a.m. to 12:30 a.m., the second (b) from 12:30 a.m. to $4: 30$ p.m., and the third (c) from 4:30 p.m. to 6:30 p.m.

Thus, the Potential Energy Benchmark has been calculated for each lecture room $(i)$, for the three timeslots $(t)$ and for each season $(s)$.

The PEB can be expressed as the Eq. (1):

$P E B_{i, t, s}=E R_{i, t, s}+T R_{i, t, s}$

The following sections well explain the contribution of the two terms.

\subsection{Electrical requirement}

The power $(P)$ and the number of lamps $(L)$ are the terms used to calculate the electrical energy requirement of a lecture room $(E R)$. However, the operating hours of the lighting devices do not correspond to the teaching hours. According to the features of the lecture room, the solar intake influences the use of lamps. During the winter, the hypothesis is that the lamps will be all switched on in the early morning and evening, while a percentage of them will be on in the middle of the day, thanks to solar intake. On the other hand, during the summer a minimal percentage of lamps will be on during the day, e.g. in the lecture rooms oriented to the north. The percentage of power on $(y)$ depends on the cardinal orientation $(c)$, on the season $(s)$ and on the day timeslot $(t)$. The Electrical Requirement $(E R)$ of a lecture room $i$, in the timeslot $t$ and for the season $s$, can be formulated as follows:

$E R_{i, t, s}=\left(\sum_{1}^{n} P_{n} \cdot L_{n}\right) \cdot y_{t, s, c}$

\subsection{Thermal requirement}

The thermal requirement is different during the winter and during the summer. The thermal requirement is zero during the mid-seasons, as explained previously. According to K. Song et al., it is difficult to simulate the thermodynamics of a building by a simulation model. The model would require too 
many external and internal information and it would reveal as time-expensive. Therefore, the thermal requirement is designed on the basis of the Decree n. 6480 [9], even if the original model has been simplified. The PEB expresses the energy potentially required in one operating hour. Thus, some variables are adjusted to take back the thermal requirement at only one-hour of lecture room utilization.

Solar intake influences the thermal energy requirement, and not only the electrical energy. During winter, the lecture rooms will require more energy in the morning and evening, while the solar intake will support the heating system in the middle of the day. Vice versa, during summer. A coefficient has been introduced to take into account the percentage of utilization of the heating system $(x)$. The coefficient is indirectly balanced to the solar intake in winter, and directly proportioned in summer.

(1) Winter

For the winter season, the thermal energy requirement $(T R w)$ is expressed as follows:

$T R w_{i, t, s}=Q_{h} \cdot x_{t, s, c}$

The heating requirement $Q_{h}$ is expressed as:

$Q_{h}=0.024 \cdot D D \cdot\left(H_{t}+H_{v}\right)-f_{x} \cdot\left(Q_{s}+Q_{i n t}\right)$

The heating requirement is composed by two main terms. The first one is the heating required by the lecture room for transmission $\left(0.024^{*} D D^{*} H t\right)$ and for ventilation $\left(0.024^{*} D D^{*} H v\right)$, according to the building structure. The second one considers the contribution of the free intake of sun $(Q s)$ and the free intake from the utilization of the lecture room itself (Qint). Then, the last two terms are multiplied by the utilization factor of heat losses $(f x)$.

The formulation of each term of the Eq. (4) are shown hereafter. Inside the lecture rooms, the temperature is set to $20^{\circ} \mathrm{C}$. Day degrees are calculated as the sum of the differences between the set point and the outside temperature $(\mathrm{Te})$, for all of the periods considered, as in Eq. (5).

$D D=\sum_{1}^{b}\left(20-T_{e}\right)$

The coefficient of heat exchange for transmission is found by multiplying the dimension of surface $S_{j}$, by the transmittance $U$ of the surface $j$. The resulting value had to be adjusted by an additional parameter, $B$, that considers the heat exchange between the heated room and the next not-heated room, as in Eq. (6).

$H_{t}=\sum_{1}^{i} S_{j} \cdot U_{i} \cdot B_{t r, i}$

The coefficient of heat exchange for ventilation is found by multiplying the thermal capacity volume of the air $\left(\rho a^{*} c a\right)$ by the total daily flow rate of air due to natural ventilation, $V a, k$, as in Eq. (7).

$H_{v}=\rho_{a} \cdot c_{a} \cdot \sum_{k} V_{a, k}$

The free solar and inside intakes must be subtracted by the heating requirement for transmission and ventilation. Eq. (8) and Eq. (9) allow the calculation of the free intake of sun $(Q s)$ and the free intake inside the lecture room (Qint).

$Q_{s}=r \cdot \sum_{\text {ex }} I_{\text {sun }, e x} \cdot S_{w, j}$
$Q_{\text {int }}=\left(\varphi_{\text {int }} \cdot A_{f l} \cdot h\right) / 1000$

\section{(2) Summer}

During the summer, the cooling system is on and the heating system is switched off. The formula allows to calculate the cooling requirement and it is quite similar to the formula for the heating requirement, i.e. Eq. (10): terms are the same. The difference is that energy requirements $(Q t+Q v)$ have to be subtracted by the free solar and inside intake $(Q s+Q i n t)$, Eq. (11). The free intakes warm up the lecture room and the energy request are necessary to reduce inside temperature. In summer, temperature set point is $25^{\circ} \mathrm{C}$.

$$
\begin{aligned}
& T R s_{i, t, s}=Q_{c} \cdot x_{t, s, c} \\
& Q_{c}=\max \left[0 ;\left(Q_{s}+Q_{\text {int }}\right)-f_{x} \cdot\left(Q_{t}+Q_{v}\right)\right]
\end{aligned}
$$

The amount of energy required is calculated as the sum of the cooling requirement for transmission, Eq. (12) and for ventilation, Eq. (15).

The energy exchanged between the climate-controlled area and the surrounding is the sum of the energy request for transmission $\left(H t^{*} \Delta \theta^{*} \Delta t\right)$ and the energy transferred by surface radiation $(Q t, s)$. The energy transferred by surface radiation is partly calculated in the term $H t$, while $Q t, s$ is considered null in this paper. This simplified solution is due to the intended preliminary design of the present contribution.

$Q_{t}=\left(H_{t} \cdot \Delta \theta \cdot \Delta t\right)+Q_{t, s}$

In Eq. (12), the term $\Delta \theta$ indicates the difference between the set point temperature of the thermal zone $(\theta i)$, and the average outdoor temperature, calculated as the monthly mean $(\theta e)$, Eq. (13).

$\Delta \theta=\theta_{i}-\theta_{e}$

The month length $\Delta t$ is calculated as in Eq. (14). The PEB is a daily value, thus the monthly heating requirement is recalculated on a daily basis.

$\Delta t=\frac{24 \cdot N_{Z}}{1000}$

The following Eq. (15) shows the amount of energy, dissipated by ventilation, between the climate-controlled area and the surrounding environment:

$Q_{v}=\left(H_{v} \cdot \Delta \theta \cdot \Delta t\right)$

(3) Electrical and thermal coefficients

The coefficients adjust the energy requirements as a function of the percentage of use of the electrical and thermal systems. The solar intake and irradiance have an impact on the percentage of use. The solar intake and irradiance change during the timeslot and the season. Thus, the percentage of use changes according to season, timeslot and type of energy (electrical of thermal). The authors have estimated the coefficients value.

Table 1 summarizes the electrical coefficients used for the calculation of the electrical energy requirement in winter. Lecture rooms oriented to the North will require more electrical energy during the day, with respect to the lecture rooms exposed to the other cardinal points. The entire lighting 
system will be switched on in the evening for all of the lecture rooms. The lower the solar intake, the higher the electrical and heating system load. The higher the solar intake, the lower the electrical and heating system load.

Table 1. Electrical coefficients for winter

\begin{tabular}{ccccc}
\hline & North & South & Est & West \\
\hline $\mathrm{a}$ & 0.7 & 0.2 & 0.2 & 0.4 \\
$\mathrm{~b}$ & 0.7 & 0.2 & 0.4 & 0.2 \\
$\mathrm{c}$ & 1 & 1 & 1 & 1 \\
\hline
\end{tabular}

During the winter season, the same trend may be observed for the thermal coefficients. The North exposure is characterized by a high requirement of the thermal system, as well as the evening timeslot, Table 2 .

Table 2. Thermal coefficients for winter

\begin{tabular}{ccccc}
\hline & North & South & Est & West \\
\hline $\mathrm{a}$ & 0.9 & 0.6 & 0.7 & 0.8 \\
$\mathrm{~b}$ & 0.9 & 0.7 & 0.8 & 0.7 \\
$\mathrm{c}$ & 1 & 1 & 1 & 1 \\
\hline
\end{tabular}

The lighting system will be used less during summer. The solar intake will reduce the use of lamps, too. The percentage of use in summer is shown in Table 3.

Table 3. Electrical coefficients for summer

\begin{tabular}{ccccc}
\hline & North & South & Est & West \\
\hline $\mathrm{a}$ & 0.4 & 0 & 0 & 0.2 \\
$\mathrm{~b}$ & 0.4 & 0 & 0.2 & 0 \\
$\mathrm{c}$ & 0.6 & 0.2 & 0.4 & 0 \\
\hline
\end{tabular}

In summer, thermal coefficients are directly proportioned to the solar intake. The higher the solar intake, the higher the utilization of the cooling system, while the lower the solar intake, the lower the utilization of the cooling system, as in Table 4.

Table 4. Thermal coefficients for summer

\begin{tabular}{ccccc}
\hline & North & South & Est & West \\
\hline $\mathrm{a}$ & 0.4 & 0.8 & 0.7 & 0.5 \\
$\mathrm{~b}$ & 0.5 & 1 & 0.5 & 0.7 \\
$\mathrm{c}$ & 0.2 & 0.6 & 0.4 & 0.4 \\
\hline
\end{tabular}

Table 5 summarizes the Potential Energy Benchmark calculated for each lecture room, for each month and timeslot.

Table 5. PEB for each lecture room, month and timeslot

\begin{tabular}{|c|c|c|c|c|c|c|c|}
\hline PEB & N1 & $\mathrm{N} 2$ & N3 & N4 & N5 & N6 & N7 \\
\hline Feb_a & 3,69 & 3,76 & 3,69 & 3,8 & 2,17 & 1,3 & 1,25 \\
\hline Feb_b & 3,16 & 3,22 & 3,16 & 3,2 & 2,52 & 1,5 & 1,46 \\
\hline Feb_c & 4,85 & 4,94 & 4,85 & 4,9 & 3,27 & 1,9 & 1,90 \\
\hline Mar_a & 5,46 & 5,57 & 5,46 & 5,6 & 3,24 & 1,9 & 1,86 \\
\hline Mar_b & 4,71 & 4,80 & 4,71 & 4,8 & 3,74 & 2,2 & 2,16 \\
\hline Mar_c & 7,07 & 7,20 & 7,07 & 7,2 & 4,80 & 2,8 & 2,78 \\
\hline Apr_a & 1,81 & 1,84 & 1,81 & 1,8 & 1,02 & 0,6 & 0,59 \\
\hline Apr_b & 1,51 & 1,54 & 1,51 & 1,5 & 1,20 & 0,7 & 0,71 \\
\hline Apr_c & 2,50 & 2,55 & 2,50 & 2,5 & 1,62 & 1,0 & 0,96 \\
\hline May_a & 0,10 & 0,10 & 0,10 & 0,1 & 0,00 & 0,00 & 0,00 \\
\hline May_b & 0,00 & 0,00 & 0,00 & 0,00 & 0,05 & 0,00 & 0,03 \\
\hline May_c & 0,00 & 0,00 & 0,00 & 0,00 & 0,10 & 0,1 & 0,06 \\
\hline Jun_a & 0,64 & 0,64 & 0,64 & 0,6 & 0,54 & 0,3 & 0.30 \\
\hline Jun_b & 0,75 & 0,76 & 0,75 & 0,8 & 0,44 & 0,2 & 0.25 \\
\hline Jun_c & 0,43 & 0,44 & 0,43 & 0,4 & 0,41 & 0,2 & 0,23 \\
\hline PEB & N8 & N9 & N10 & N11 & TA & TB & $\mathrm{TC}$ \\
\hline Feb_a & 2,14 & 4,11 & 2,51 & 3,02 & 2,88 & 2,93 & 3,17 \\
\hline Feb_b & 2,50 & 4,11 & 2,51 & 3,02 & 3,36 & 3,41 & 1,31 \\
\hline Feb_c & 3,29 & 4,63 & 2,84 & 3,39 & 4,39 & 4,45 & 1,77 \\
\hline Mar_a & 3,19 & 6,11 & 3,71 & 4,52 & 4,30 & 4,37 & 4,59 \\
\hline Mar_b & 3,70 & 6,11 & 3,71 & 4,52 & 4,98 & 5,06 & 1,78 \\
\hline Mar_c & 4,79 & 6,85 & 4,17 & 5,05 & 6,42 & 6,52 & 2,48 \\
\hline Apr_a & 1,01 & 2,50 & 1,60 & 1,79 & 1,36 & 1,38 & 2,36 \\
\hline Apr_b & 1,21 & 2,50 & 1,60 & 1,79 & 1,62 & 1,64 & 1,04 \\
\hline Apr_c & 1,67 & 2,84 & 1,83 & 2,02 & 2,21 & 2,24 & 1,37 \\
\hline May_a & 0,00 & 0,11 & 0,09 & 0,05 & 0,00 & 0,00 & 0,38 \\
\hline May_b & 0,06 & 0,11 & 0,09 & 0,05 & 0,08 & 0,08 & 0,38 \\
\hline May_c & 0,13 & 0,17 & 0,13 & 0,07 & 0,15 & 0,15 & 0,38 \\
\hline Jun_a & 0,54 & 0,20 & 0,09 & 0,14 & 0,71 & 0,72 & 0,38 \\
\hline Jun_b & 0,45 & 0,22 & 0,09 & 0,16 & 0,59 & 0,59 & 0,38 \\
\hline Jun_c & 0,44 & 0,21 & 0,13 & 0,12 & 0,56 & 0,56 & 0,38 \\
\hline PEB & Cons & MTA & MTB & M1 & MLAB1 & MLAB2 & ELE1 \\
\hline Feb_a & 1,07 & 1,91 & 3,54 & 4,71 & 1,91 & 3,54 & 3,02 \\
\hline Feb_b & 0,54 & 2,22 & 3,54 & 4,71 & 2,22 & 3,54 & 3,02 \\
\hline Feb_c & 0,68 & 3,51 & 4,04 & 5,34 & 3,51 & 4,04 & 3,39 \\
\hline Mar_a & 1,48 & 3,00 & 5,18 & 6,95 & 3,00 & 5,18 & 4,52 \\
\hline Mar_b & 0,68 & 3,48 & 5,18 & 6,95 & 3,48 & 5,18 & 4,52 \\
\hline Mar_c & 0,88 & 5,32 & 5,86 & 7,83 & 5,32 & 5,86 & 5,05 \\
\hline Apr_a & 0,83 & 1,28 & 2,41 & 3,12 & 1,28 & 2,41 & 1,79 \\
\hline
\end{tabular}




\begin{tabular}{|c|c|c|c|c|c|c|c|}
\hline Apr_b & 0,47 & 1,48 & 2,41 & 3,12 & 1,48 & 2,41 & 1,79 \\
\hline Apr_c & 0,56 & 2,46 & 2,78 & 3,57 & 2,46 & 2,78 & 2,02 \\
\hline May_a & 0,28 & 0,00 & 0,19 & 0,19 & 0,00 & 0,19 & 0,05 \\
\hline May_b & 0,28 & 0,00 & 0,19 & 0,19 & 0,00 & 0,19 & 0,05 \\
\hline May_c & 0,28 & 0,10 & 0,29 & 0,29 & 0,10 & 0,29 & 0,07 \\
\hline Jun_a & 0,28 & 0,00 & 0,19 & 0,19 & 0,00 & 0,19 & 0,14 \\
\hline Jun_b & 0,28 & 0,00 & 0,19 & 0,19 & 0,00 & 0,19 & 0,16 \\
\hline Jun_c & 0,28 & 0,10 & 0,29 & 0,29 & 0,10 & 0,29 & 0,12 \\
\hline PEB & ELE2 & B0.3 & B0.4 & B 0.5 & B1.1 & B1.2 & B1.4 \\
\hline Feb_a & 3,02 & 0,49 & 1,13 & 1,70 & 1,17 & 1,22 & 0,44 \\
\hline Feb_b & 3,02 & 0,56 & 0,95 & 1,70 & 1,17 & 1,22 & 0,55 \\
\hline Feb_c & 3,39 & 0,95 & 1,51 & 1,93 & 1,33 & 1,38 & 0,44 \\
\hline Mar_a & 4,52 & 0,96 & 1,66 & 2,50 & 1,73 & 1,80 & 0,93 \\
\hline Mar_b & 4,52 & 1,12 & 1,42 & 2,50 & 1,73 & 1,80 & 1,16 \\
\hline Mar_c & 5,05 & 1,74 & 2,17 & 2,82 & 1,94 & 2,03 & 0,80 \\
\hline Apr_a & 1,79 & 0,19 & 0,27 & 0,90 & 0,59 & 0,62 & 0,14 \\
\hline Apr_b & 1,79 & 0,22 & 0,21 & 0,90 & 0,59 & 0,62 & 0,17 \\
\hline Apr_c & 2,02 & 0,46 & 0,44 & 1,05 & 0,69 & 0,71 & 0,21 \\
\hline May_a & 0,05 & 0,00 & 0,04 & 0,08 & 0,05 & 0,05 & 0,00 \\
\hline May_b & 0,05 & 0,00 & 0,00 & 0,08 & 0,05 & 0,05 & 0,00 \\
\hline May_c & 0,07 & 0,04 & 0,00 & 0,12 & 0,07 & 0,07 & 0,02 \\
\hline Jun_a & 0,14 & 0,44 & 0,58 & 0,29 & 0,22 & 0,22 & 0,28 \\
\hline Jun_b & 0,16 & 0,55 & 0,75 & 0,34 & 0,26 & 0,27 & 0,33 \\
\hline Jun_c & 0,12 & 0,37 & 0,43 & 0,23 & 0,16 & 0,16 & 0,49 \\
\hline PEB & B1.5 & B1.6 & B1.7 & B1.8 & B1.9 & B2.1 & B2.2 \\
\hline Feb_a & 0,43 & 1,12 & 0,47 & 0,45 & 0,45 & 0,72 & 0,44 \\
\hline Feb_b & 0,54 & 0,95 & 0,57 & 0,55 & 0,55 & 0,87 & 0,53 \\
\hline Feb_c & 0,43 & 1,50 & 0,29 & 0,28 & 0,28 & 0,46 & 0,27 \\
\hline Mar_a & 0,91 & 1,66 & 0,68 & 0,65 & 0,66 & 1,03 & 0,63 \\
\hline Mar_b & 1,14 & 1,42 & 0,83 & 0,80 & 0,81 & 1,25 & 0,78 \\
\hline Mar_c & 0,79 & 2,16 & 0,39 & 0,38 & 0,38 & 0,62 & 0,37 \\
\hline Apr_a & 0,14 & 0,27 & 0,25 & 0,24 & 0,24 & 0,40 & 0,23 \\
\hline Apr_b & 0,17 & 0,20 & 0,29 & 0,28 & 0,28 & 0,48 & 0,27 \\
\hline Apr_c & 0,21 & 0,43 & 0,18 & 0,17 & 0,17 & 0,31 & 0,17 \\
\hline May_a & 0,00 & 0,04 & 0,03 & 0,03 & 0,03 & 0,06 & 0,03 \\
\hline May_b & 0,00 & 0,00 & 0,03 & 0,03 & 0,03 & 0,06 & 0,03 \\
\hline May_c & 0,02 & 0,00 & 0,05 & 0,05 & 0,05 & 0,10 & 0,05 \\
\hline Jun_a & 0,28 & 0,57 & 0,38 & 0,37 & 0,38 & 0,50 & 0,37 \\
\hline Jun_b & 0,33 & 0,75 & 0,38 & 0,37 & 0,38 & 0,50 & 0,37 \\
\hline Jun_c & 0,49 & 0,43 & 0,44 & 0,43 & 0,43 & 0,58 & 0,42 \\
\hline PEB & B2.4 & B2.5 & B2.6 & B2.7 & B2.8 & B2.9 & B2.10 \\
\hline Feb_a & 0,44 & 0,44 & 1,12 & 0,48 & 0,44 & 0,47 & 0,58 \\
\hline Feb_b & 0,55 & 0,54 & 0,95 & 0,58 & 0,54 & 0,58 & 0,70 \\
\hline Feb_c & 0,44 & 0,43 & 1,51 & 0,29 & 0,27 & 0,29 & 0,37 \\
\hline Mar_a & 0,93 & 0,93 & 1,66 & 0,69 & 0,64 & 0,68 & 0,83 \\
\hline Mar_b & 1,16 & 1,15 & 1,42 & 0,85 & 0,79 & 0,84 & 1,02 \\
\hline Mar_c & 0,80 & 0,80 & 2,17 & 0,40 & 0,37 & 0,39 & 0,50 \\
\hline Apr_a & 0,14 & 0,14 & 0,27 & 0,25 & 0,23 & 0,25 & 0,32 \\
\hline Apr_b & 0,17 & 0,17 & 0,21 & 0,30 & 0,28 & 0,30 & 0,38 \\
\hline Apr_c & 0,21 & 0,21 & 0,44 & 0,18 & 0,17 & 0,18 & 0,24 \\
\hline May_a & 0,00 & 0,00 & 0,04 & 0,03 & 0,03 & 0,03 & 0,05 \\
\hline May_b & 0,00 & 0,00 & 0,00 & 0,03 & 0,03 & 0,03 & 0,05 \\
\hline May_c & 0,02 & 0,02 & 0,00 & 0,05 & 0,05 & 0,05 & 0,07 \\
\hline Jun_a & 0,28 & 0,28 & 0,57 & 0,39 & 0,37 & 0,38 & 0,44 \\
\hline Jun_b & 0,33 & 0,33 & 0,75 & 0,39 & 0,37 & 0,38 & 0,44 \\
\hline Jun_c & 0,49 & 0,49 & 0,43 & 0,44 & 0,42 & 0,44 & 0,51 \\
\hline PEB & B3.1 & V1 & CAD & BLAB 1 & BLAB2 & & \\
\hline Feb_a & 0,72 & 1,91 & 3,02 & 0,47 & 0,47 & & \\
\hline Feb_b & 0,87 & 2,22 & 3,02 & 0,58 & 0,58 & & \\
\hline Feb_c & 0,46 & 3,51 & 3,39 & 0,29 & 0,29 & & \\
\hline Mar_a & 1,03 & 3,00 & 4,52 & 0,68 & 0,68 & & \\
\hline Mar_b & 1,26 & 3,48 & 4,52 & 0,84 & 0,84 & & \\
\hline Mar_c & 0,62 & 5,32 & 5,05 & 0,39 & 0,39 & & \\
\hline Apr_a & 0,41 & 1,28 & 1,79 & 0,25 & 0,25 & & \\
\hline Apr_b & 0,48 & 1,48 & 1,79 & 0,30 & 0,30 & & \\
\hline Apr_c & 0,31 & 2,46 & 2,02 & 0,18 & 0,18 & & \\
\hline May_a & 0,06 & 0,00 & 0,05 & 0,03 & 0,03 & & \\
\hline May_b & 0,06 & 0,00 & 0,05 & 0,03 & 0,03 & & \\
\hline May_c & 0,10 & 0,10 & 0,07 & 0,05 & 0,05 & & \\
\hline
\end{tabular}




$\begin{array}{llllll}\text { Jun_a } & 0,50 & 0,00 & 0,14 & 0,38 & 0,38 \\ \text { Jun_b } & 0,50 & 0,00 & 0,16 & 0,38 & 0,38 \\ \text { Jun_c } & 0,58 & 0,10 & 0,12 & 0,44 & 0,44\end{array}$

\section{CURRENT ENERGY USE}

The software Easy Accademy, by Zucchetti, is currently used to assess the timetabling at the University of Brescia. The comparison has been performed for the second semester of 2018, at the Engineering facilities. The second semester of 2018 began the second week of February and finished at the end of June. Thus, the second semester included three seasons. The lecture rooms used only electrical energy during spring. The Engineering facilities are located in three buildings, which have been built in different periods and, consequently, the structures are different.

Table 6 sums up the main data.

Table 6. Current main data

\begin{tabular}{ccc}
\hline Data & \multicolumn{2}{c}{ Value } \\
\hline Number of lectures & \multicolumn{2}{c}{184} \\
Number of total hours & \multicolumn{2}{c}{1,056} \\
supplied & Number of & Lecture rooms \\
Lecture room & lecture rooms & capacity \\
Small & 19 & 50 \\
Medium & 15 & 100 \\
Big & 14 & 265 \\
\hline
\end{tabular}

The semester energy consumption (ECS) has been calculated adding, for each lecture, the product between the PEB and the lecture working hours $(h l, i)$ planned for the assigned lecture room $i$.

$E C s=\sum_{1}^{l} \sum_{1}^{i} P E B_{i, t, s} \cdot h_{l, i}$

Table 7 summarizes the results. The thermal and electrical energy have different units of measure; thus the values have been converted in toe (ton of oil equivalent) so as to sum them.

Table 7. Results of current timetable

\begin{tabular}{ccccc}
\hline & $\begin{array}{c}\text { Total } \\
\text { cons. } \\
{[\mathbf{m t o e}]}\end{array}$ & $\begin{array}{c}\text { Total } \\
\text { Cost [€] }\end{array}$ & $\begin{array}{c}\text { Thermal } \\
\text { Cons. } \\
{[\mathbf{k W h t ]}}\end{array}$ & $\begin{array}{c}\text { Electrical } \\
\text { Cons.[kWhe] }\end{array}$ \\
\hline February & $5,885.11$ & $12,222.63$ & $50,350.50$ & $3,776.54$ \\
March & $11,760.24$ & $24,424.52$ & $100,615.57$ & $7,546.68$ \\
April & $4,193.69$ & $8,709.76$ & $35,879.42$ & $2,691.14$ \\
May & 197.73 & 410.67 & 0 & $1,057.14$ \\
June & $1,514.00$ & $3,144.39$ & $12,953.17$ & 971.55 \\
ECs & $23,550.79$ & $48,911.96$ & $199,798.66$ & $16,043.32$ \\
\hline
\end{tabular}

As shown in Table 7, the consumption valued for February is lower than March for two reasons. The first is that March had four working weeks, instead of the three working weeks of February. The second is that the day degrees of February were lower than in March. The valued consumption decreases in May because the thermal energy system was switched off during spring (only the electrical energy system was switched on). In May, day degrees decrease and the PEB is lower than in April, thus energy consumption is lower in May. In June, the cooling system is switched on and the energy consumption increases once again.

\section{NEW TIMETABLE PROPOSAL}

Two timetable proposals will be presented. The second semester has been divided into two different timetables to better optimize energy consumption. The first timetable is for February, March and April, whereas the second is for May and June. The PEB changes during the seasons, thus a lecture room could be energy efficient in winter but it could be not so efficient in summer. The lecture room energy ranking changes between winter and summer and, consequently, the proposal is in favour of a shift at the half of the semester.

The new timetable proposal has been built using an assignment algorithm, Figure 1 . The algorithm verifies the student enrolment to a lecture and it considers just the lecture rooms that meet the capacity required. Then, the algorithm assigns the lecture room, the timeslot and the day with the lower PEB to the lecture. Three lessons of two hours during the week have been assigned to each lecture. Then, the algorithm verifies that no overlap occurs among the lecture rooms, and timeslots, and professors. The professors could have more than one course, in the same semester. If an overlap takes place, the algorithm modifies the timetable. Firstly, the algorithm checks if the lecture room is available in the same timeslot in another day. If the lecture room is available, the algorithm assigns the new day. The reason is that the first assignment is based on the lower PEB possible, and any shift implies a worsening of the energy consumption. If the lecture room is not available, the day, lecture room and timeslot will be changed.

The hard constraints have been met. Indeed, no overlaps are permitted. The soft constraints have been relaxed, e.g. the lesson length is not a professor's choice, lunch break is not always available for students, professors cannot express a preference about timeslot, day or lecture room.

Table 8 shows the results of the timetable proposal.

Table 8. Results of new timetable

\begin{tabular}{ccccc}
\hline & $\begin{array}{c}\text { Total } \\
\text { cons. } \\
{[\mathbf{m t o e}]}\end{array}$ & $\begin{array}{c}\text { Total Cost } \\
{[\boldsymbol{\epsilon}]}\end{array}$ & $\begin{array}{c}\text { Thermal } \\
\text { Cons. } \\
{[\mathbf{k W h t ]}}\end{array}$ & $\begin{array}{c}\text { Electrical } \\
\text { Cons. } \\
{[\mathbf{k W h e}]}\end{array}$ \\
\hline Winter & $17.540,64$ & $36.429,66$ & $150.070,15$ & $11.256,03$ \\
Summer & $1.214,88$ & $2.523,16$ & $10.394,02$ & 779,60 \\
ECs & $18.755,53$ & $38.952,82$ & $160.464,17$ & $12.035,63$ \\
\hline
\end{tabular}

The saving of energy consumption is about $20 \%$. Thermal energy savings are about $40,000 \mathrm{kWht}$, while electrical energy savings are close to $4,000 \mathrm{kWhe}$. Monetary savings are about $10,000 €$, for one semester, for the Engineering facilities. The $\mathrm{CO}_{2}$ not released in atmosphere is estimated in 22 tons of equivalent $\mathrm{CO}_{2}$. 


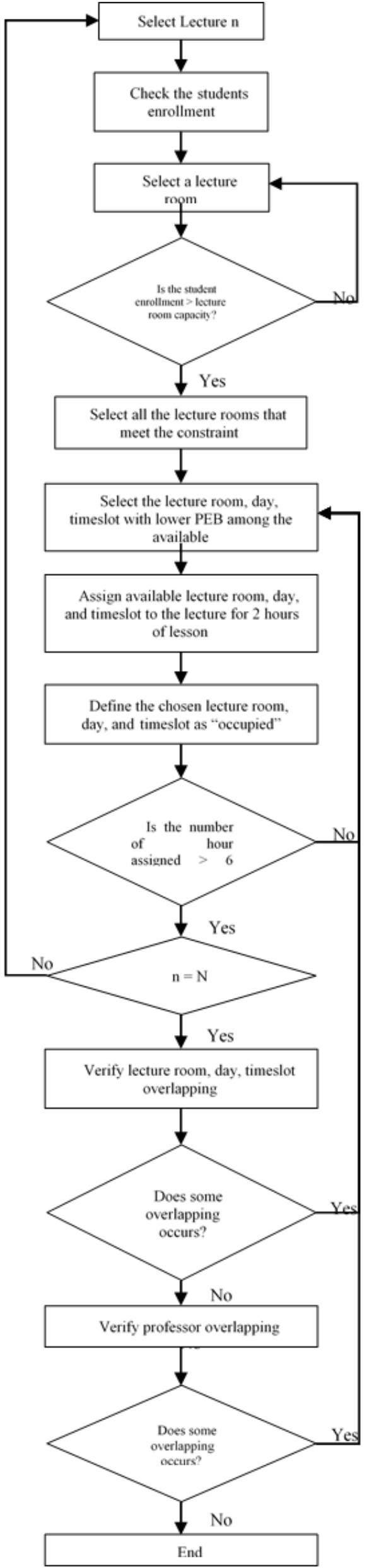

Figure 1. Flowchart of the algorithm

\section{CONCLUSIONS}

University buildings must be managed in an optimal way to optimize energy consumption and environmental footprint. The energy featuring of a lecture room is of primary importance for reducing energy use. The timetabling problem, in the authors' opinion, should encompass the constraints concerning the energy consumption of lecture rooms. This paper proposes to rank the lecture rooms according to the Potential Energy Benchmark. The PEB is an index of the energy use and quality of the lecture room. The PEB allows to classify lecture rooms and to assess the priority of assignment to the lecture room which is more energy efficient. Using the $\mathrm{PEB}$, a timetable proposal has been presented. The new timetable allows a reduction of the energy used for teaching activities close to $20 \%$.

The PEB value is not easy to be calculated and it can increase the time to perform the timetable. However, the PEB is calculated once and then it remains the same until buildings will be renovated. The proposed PEB is an earliest analysis and it needs to be studied in deep and from different points of view. The assessment of the PEB will be reviewed using thermodynamics simulation software (e.g. EnergyPlus). The workrooms and the HVAC system will be included in the assessment of electrical energy use. Those analyses will allow to answer questions such as: does a precise index increase the accuracy of the energy timetable problem? The timetabling problem will be solved using different algorithms, i.e. genetic algorithms or tabu search. This analysis will allow to reply to another question: can a different algorithm optimize the problem and still reduce energy use? In the authors' opinion, it would be interesting to overlap the energy demand profiles with the occupancy patterns of lecture rooms and university buildings. The matching would allow to identify additional energy wastes and rescheduling lecture rooms to reduce or avoid them. The non-operating time between lessons has to be further investigated to optimize the scheduling of lecture rooms and to reduce the related energy use.

The topics above are significant, but the results, obtained in the present preliminary contribution, suggest opportunity for improvement.

\section{REFERENCES}

[1] DECRETO LEGISLATIVO 4 luglio 2014, n. 102. Attuazione della direttiva 2012/27/UE sull'efficienza energetica, che modifica le direttive 2009/125/CE e 2010/30/UE ed abroga le direttive 2004/8/CE e 2006/32/CE.

[2] Yang Z, Barcerik-Gerber B. (2014). The coupled effects of personalized occupancy profile based HAVC schedule and room reassignment on building energy use. Energy and Buildings 77: 113-122. https://doi.org/10.1016/j.enbuild.2014.04.002

[3] Gul MS, Patidar S. (2014). Understanding the energy consumption and occupancy of a multi-purpose academic building. Energy and Buildings 87: 155-165. https://doi.org/10.1016/j.enbuild.2014.11.027

[4] Pan S, Wang XR, Wei S, Xu CQ, Zhang XX, Xie JC, Tindall J, Wilde P. (2017). Energy waste in buildings due to occupant behaviour. Energy Procedia 105: 2233-2238. https://doi.org/10.1016/j.egypro.2017.03.63

[5] Masoso OT, Groble LJ. (2010). The dark side of 
occupants' behaviour on building energy use. Energy and Buildings 42(2): 173-177. https://doi.org/10.1016/j.enbuild.2009.08.009

[6] Majumdar A, Zhang ZR, Albonesi DH. (2016). Characterizing the benefits and limitations of smart building meeting room scheduling. Presented at Conference IEEE Available: 978-1-5090-1772-0.

[7] Song K, Kim S, Park M, Lee HS. (2017). Energy efficiency-based course timetabling for university buildings. $\quad$ Energy 139: 394-405. https://doi.org/10.1016/j.energy.2016.07.176.

[8] Sethanan K, Theerakulpisut S, Benjapiyaporn C. (2014). Improving energy efficiency by lecture room scheduling: a case study in a Thai University. Advanced Material Research 931-932: 1089-1095. https://doi.org/10.4028/www.scientific.net/AMR.931932.1089

[9] Decreto n. 6480 del 30 luglio 2015 - Allegato H- Metodo di Calcolo - Disposizioni in merito alla Disciplina per l'efficienza energetica degli edifici e per il relativo attestato di prestazione energetica a seguito della DGR 3868 del 17.7.2015

\section{NOMENCLATURE}

a stands for air

Afl surface of the floor $\left[\mathrm{m}^{2}\right]$

$\mathrm{Btr}, \mathrm{i}$ dimensionless, adjustment element of heating exchange between the heated room and the notheated one (value supplied by the Standard UNI TS 113000-1:2014)

c denotes the cardinal orientation, dimensionless

d day of the period, number

DD Degree Day

ECs semester energy consumption [kWh]

ER stands for Electrical Requirement per hour $[\mathrm{kWh} / \mathrm{h}]$

fx utilization factor of heat losses, depending on the thermal inertia of the building and the ratio between free inputs and dispersions, assumed equal to 0.95 , dimensionless

$\mathrm{h} \quad$ number of hours of heating season [h]

hl,i working hours of lecture 1 in lecture room i, [h]

$\mathrm{Ht}$ coefficient of transmission, heat exchange $\left[\mathrm{W} /{ }^{\circ} \mathrm{K}\right]$
$\mathrm{Hv}$ coefficient of ventilation, heat exchange $\left[\mathrm{W} /{ }^{\circ} \mathrm{K}\right]$

i denotes the lecture room, dimensionless

j number of surfaces, dimensionless

Isun,ex total seasonal irradiance (in the heating period) on the vertical plane $\left[\mathrm{kWh} / \mathrm{m}^{2}\right]$, for each $\mathrm{x}$-th exposure.

$\mathrm{k}$ single and specific air exchange for ventilation, dimensionless

L number of lamps

1 number of lectures of the semester, i.e. 184, dimensionless

$\mathrm{n} \quad$ denotes the type of lamps in a lecture room

$\mathrm{Nz}$ the number of days in the $\mathrm{z}$-month considered, assuming the daily energy requirement, the coefficient will have a unitary value

$\mathrm{P} \quad$ power of the lamp $[\mathrm{kW}]$

$\mathrm{Q}$ int free internal intake

Qc denotes the cooling requirement $[\mathrm{kWh} / \mathrm{h}]$

$\mathrm{Qh} \quad$ denotes the heating requirement $[\mathrm{kWh} / \mathrm{h}]$

$\mathrm{r} \quad$ reduction adjustment element, taking into account the presence of transparent elements and medium shading, set to 0.2 , dimensionless

$\mathrm{s} \quad$ denotes the season, dimensionless

$\mathrm{Sj} \quad$ dimension of surface $\mathrm{j}\left[\mathrm{m}^{2}\right]$

$\mathrm{Sw}, \mathrm{j} \quad$ window area of surface $\mathrm{j}\left[\mathrm{m}^{2}\right]$

$\mathrm{t}$ denotes the timeslot, dimensionless

Te external temperature $\left[{ }^{\circ} \mathrm{K}\right]$

TR stands for Thermal Energy Requirement $[\mathrm{kWh} / \mathrm{h}]$

$\mathrm{Ui} \quad$ transmittance of surface $\mathrm{I}\left[\mathrm{W} / \mathrm{m}^{2}{ }^{\circ} \mathrm{K}\right]$

Va,k k-th average daily air flow rate due to natural ventilation or aeration and / or infiltration of the area or mechanical ventilation, $\left[\mathrm{m}^{3} / \mathrm{s}\right]$

$\mathrm{x} \quad$ coefficient for the percentage of heating system switched on

y coefficient for the percentage of lamps switched on, dimensionless

$\theta \mathrm{e} \quad$ average monthly value of the daily outdoor temperature $\left[{ }^{\circ} \mathrm{K}\right.$ ]

$\theta \mathrm{i} \quad$ Setting of the internal temperature of the thermal zone considered $\left[{ }^{\circ} \mathrm{K}\right]$

$\rho \mathrm{a}^{*} \mathrm{ca} \quad$ volume thermal capacity of the air, equal to 0.34

pint input produced by the internal heat sources $\left[\mathrm{W} / \mathrm{m}^{2}\right]$ (according to the Standard UNI TS 1130001:2014, Table 7) 